\title{
Editorial
}

\section{Energy Efficiency of Manufacturing Processes and Systems-An Introduction}

\section{Konstantinos Salonitis}

Sustainable Manufacturing Systems Centre, Manufacturing Department, Cranfield University, Cranfield, Bedfordshire MK43 0AL, UK; k.salonitis@cranfield.ac.uk; Tel.: +44-1234-758347

Received: 22 May 2020; Accepted: 3 June 2020; Published: 5 June 2020

\begin{abstract}
This Special Issue of Energies was devoted to the topic of "Energy Efficiency of Manufacturing Processes and Systems". It attracted significant attention of scholars, practitioners, and policy-makers from all over the world. Eighteen papers on this topic were submitted between 2018 and 2020, and a total of 10 papers were published. Main topics included the energy efficiency improvement in both the manufacturing process and system levels. Furthermore, new methodologies and analysis approaches in developing energy efficiency were presented.
\end{abstract}

Keywords: manufacturing energy efficiency; clean manufacturing; sustainable manufacturing; digital manufacturing

\section{Introduction}

For maintaining the quality of life that has been achieved in the developed countries, manufacturing is expected to further intensify activities, and scale up production. This will be probably required even more, as demand is expected to further rise due to living quality in developing countries catching up with that of the developed ones. This obviously means that more energy, and in general more resources, will be required for the production of higher volumes of products. However, it is evident that resources are finite, and we will need to manage to produce more with less. It is clear that producing with higher energy efficiency is an absolute requirement for the years to come.

Producing with higher energy efficiency has been the focus of research in recent years and is nowadays considered one of the key decision-making attributes for manufacturing. Higher energy efficiency is one of the key drivers in delivering a low-carbon economy. This has been highlighted at both international and national levels. Energy efficiency of manufacturing is aligned to a number of United Nations' sustainable goals, such as "goal 9" that is focused on promoting sustainable industrialization, "goal 13" on taking action to combat climate change and to a degree "goal 7" on affordable and clean energy. On this basis governments have set ambitious strategic plans for decarbonization of the whole economy, impacting obviously the manufacturing sector as well. As an example, UK was the first major economy in the world to pass a net zero emissions by 2050 law. For achieving such an ambitious goal, the manufacturing sector needs to adopt more energy efficient practices.

Energy efficiency is probably among the most cost-effective measures companies can take. Energy is a variable cost, and as such, contributes to the product's cost. Reducing the energy efficiency during production can happen in a number of ways, either at the process level, through the optimization of the process parameters for example, or at the systems' level. The present Special Issue has collected papers that deal with the techniques that can be used for reducing the energy consumption in both the process and the system level.

The response to the call for papers led to 18 submitted papers, of which $10(55 \%)$ were accepted and eight $(45 \%)$ rejected. The geographical distribution of the (first) author covers six countries, and is built as follows: China (three), Finland (one), Italy (one), Korea (one), Pakistan (one), United Kingdom (three). 


\section{Background and the Special Issue}

Manufacturing energy efficiency can be approached in a number of different ways and at a number of different levels. Such levels can be more or less specific. In a number of studies five levels are considered: the device/process level, the line/cell/multi-machine system level, the facility level, the multi-factory system level and the enterprise/global supply chain level. In other studies, with a more high-level approach, two generic levels of analysis are considered, namely the manufacturing process or machine tool level and the manufacturing system level. In the analysis of the papers submitted in this Special Issue, the high-level classification is adopted.

The 10 papers collected in this Special Issue can broadly be divided into the following two categories: (a) manufacturing process energy efficiency studies, and (b) manufacturing systems energy efficiency studies. In both categories new methods and techniques for improving energy efficiency are presented. They will be described in the following subsections.

\subsection{Manufacturing Processes Energy Efficiency Studies}

A number of papers that focused on how to improve the energy efficiency of specific processes were published in this Special Issue. Papers focusing on processes such electro-discharge machining, laser drilling, laser welding and milling are included. The list of papers presented includes the following:

- Niamat, M.; Sarfraz, S.; Ahmad, W.; Shehab, E.; Salonitis, K. Parametric Modelling and Multi-Objective Optimization of Electro Discharge Machining Process Parameters for Sustainable Production. Energies 2020, 13, 38.

- Sarfraz, S.; Shehab, E.; Salonitis, K.; Suder, W. Experimental Investigation of Productivity, Specific Energy Consumption, and Hole Quality in Single-Pulse, Percussion, and Trepanning Drilling of IN 718 Superalloy. Energies 2019, 12, 4610.

- Um, J.; Stroud, I.A.; Park, Y.-K. Deep Learning Approach of Energy Estimation Model of Remote Laser Welding. Energies 2019, 12, 1799.

- $\quad$ Khan, A.M.; Jamil, M.; Salonitis, K.; Sarfraz, S.; Zhao, W.; He, N.; Mia, M.; Zhao, G. Multi-Objective Optimization of Energy Consumption and Surface Quality in Nanofluid SQCL Assisted Face Milling. Energies 2019, 12, 710.

In the following paragraphs, a brief review of these papers is provided. Niamat et al. [1] investigated the use of electro-discharge machining process for sustainable manufacturing. Their focus was on optimizing the process parameters, such as pulse on time, current and pulse off time and finding a tradeoff between quality of final produced part, productivity and cost. The work presented is mostly experimental, that led to setting up empirical models using response surface methodology for the control of the process.

Sarfraz et al. [2] focused on the laser drilling process optimization. Through a statistical design of experiments and analysis of variance (ANOVA) they presented empirical models for predicting the material removal rate, the specific energy consumption and the hole taper for the case of single pulse drilling, percussion and trepanning. A multi objective optimization algorithm was also used for the selection of the process parameters as well as the most appropriate drilling strategy.

Um et al. [3] investigated the use of deep learning for controlling the energy consumption due to remote laser welding process. Such a process is widely used in the automotive sector due to its flexibility and versatility. However, one of the key challenges when using remote laser welding is the high requirements in energy. Um et al. presented a neural network they developed using a deep learning approach for the prediction of the energy profile of the process.

Finally, Khan et al. [4] focused on the optimization of the process parameters for the energy consumption and surface quality of milling process. Two optimization methods were used, namely Grey Rational Analysis and the Non-Dominated Sorting Genetic Algorithm. The analysis followed allowed the optimization of the process parameters for reducing the energy consumption during the process. 
All the aforementioned investigations attempt to improve the energy efficiency of the respective processes while at the same time maintain or even improve the surface quality, the productivity and the cost of processing. It is evident that energy efficiency is not a goal on its own but needs to be considered in a holistic way.

\subsection{Manufacturing Systems Energy Efficiency Studies}

As mentioned, another big group of papers were focused on the manufacturing system and not on a specific process. The papers published approached this from a number of different perspectives. The list of papers presented includes the following:

- Wang, J.; Fei, Z.; Chang, Q.; Li, S. Energy Saving Operation of Manufacturing System Based on Dynamic Adaptive Fuzzy Reasoning Petri Net. Energies 2019, 12, 2216.

- Salonitis, K.; Jolly, M.; Pagone, E.; Papanikolaou, M. Life-Cycle and Energy Assessment of Automotive Component Manufacturing: The Dilemma Between Aluminum and Cast Iron. Energies 2019, 12, 2557.

- Benedetti, M.; Bonfà, F.; Introna, V.; Santolamazza, A.; Ubertini, S. Real Time Energy Performance Control for Industrial Compressed Air Systems: Methodology and Applications. Energies 2019, $12,3935$.

- Kähkönen, S.; Vakkilainen, E.; Laukkanen, T. Impact of Structural Changes on Energy Efficiency of Finnish Pulp and Paper Industry. Energies 2019, 12, 3689.

- $\quad$ Peng, C.; Peng, T.; Zhang, Y.; Tang, R.; Hu, L. Minimising Non-Processing Energy Consumption and Tardiness Fines in a Mixed-Flow Shop. Energies 2018, 11, 3382.

- Saxeena, P; Stavropoulos, P.; Kechagias, J.; Salonitis, K. Sustainability assessment for manufacturing operations. Energies 2020, 13, 2730.

In the following paragraphs, a brief review of these papers is provided. Wang et al. [5] proposed a control method for manufacturing systems based on dynamic adaptive fuzzy reasoning Petri nets. The developed method allows the characterization of the state of machines in the manufacturing system for reducing idle times. They validated their method in a manufacturing line used for the serial production of automotive powertrains.

Salonitis et al. [6] also conducted research in the automotive sector. They developed a method for assessing the importance of the energy consumed during the manufacturing phase of components, such as the engine head of a car, in the overall environmental impact of a product. Their method relies on a thorough energy audit throughout the life cycle of a product, starting from the extraction of raw materials from earth. Through this analysis they compared the energy consumption associated with production of cast iron and aluminum engine heads and assessed the impact of lightening of automotive parts.

Benedetti et al. [7] focused on industrial compressed air systems. Air compressors are among the higher energy consumers in industry. Leaks in the delivery of pressurized air results in air compressors operating for longer times as to sustain the air pressure. Furthermore, an idle compressor can still use $40 \%$ to $70 \%$ of its full load. Benedetti et al. reported that in Europe, $10 \%$ of the electrical energy consumed in industry is due to compressed air systems. In their paper they developed a method for the real time energy performance monitoring and control of air compressors. They validated their method in a real industrial environment within a pharmaceutical plant, demonstrating how adopting such methods can reduce energy consumption and associated costs.

Kähkönen et al. [8] focused on analyzing the Finish pulp and paper industry. The restructuring of the sector is presented and the impact that this had on the energy efficiency is discussed. However, they also highlighted that the restructuring accounted for $20 \%$ of the energy efficiency whereas $80 \%$ of the improvement was due to other factors. Their analysis concluded suggesting that improving the existing mills can result in higher energy savings compared to replacing them with newer ones. 
Pent et al. [9] approached the issue of energy efficiency of manufacturing systems through scheduling. For the case of a mixed-flow shop, they developed a scheduling approach for minimizing the energy consumption and tardiness fine of production. Their analysis investigated in detail the non-processing energy reduction. They validated the proposed method to a real case, and they were able to show improvements in the range of $70 \%$ for the non-processing energy.

Finally, Saxeena et al. [10] presented a holistic approach based on multi-criteria decision-making methods for assessing alternative process routes. The assessment method proposed allows the investigation of all three pillars of sustainability, namely the environmental, financial and social. For this reason, key performance indicators are proposed for each pillar and then measured or assessed. The method was demonstrated for the case of manufacturing of an automotive component that requires machining and heat treatment.

\section{Concluding Remarks and Outlook}

The Special Issue "Energy Efficiency of Manufacturing Processes and Systems" presents a collection of research articles covering relevant topics in the field. A number of different techniques and approaches were presented focusing on different levels; however, all approaches had the improvement of energy efficiency at their core.

The success of this Special Issue has motivated the editor to propose a new Special Issue that will complement the present one-Manufacturing Energy Efficiency and Industry 4.0. We invite the research community to submit novel contributions covering how Industry 4.0 and IIoT can help in improving the energy efficiency of manufacturing processes and systems.

Author Contributions: K.S. organized the Special Issue and wrote this editorial. All author have read and agreed to the published version of the manuscript.

Funding: This research did not receive any specific grant from funding agencies in the public, commercial or not-for-profit sectors.

Acknowledgments: The guest editor would like to thank the authors for submitting their excellent contributions to this Special Issue. Furthermore, the present Special Issue would not have been possible without the expert reviewers that carefully evaluated the manuscripts and provided helpful comments and suggestions for improvements. A special thank you is in order for the editors and the MDPI team for their outstanding management of this Special Issue.

Conflicts of Interest: The author declares no conflict of interest.

\section{References}

1. Niamat, M.; Sarfraz, S.; Ahmad, W.; Shehab, E.; Salonitis, K. Parametric Modelling and Multi-Objective Optimization of Electro Discharge Machining Process Parameters for Sustainable Production. Energies 2020, 13, 38. [CrossRef]

2. Sarfraz, S.; Shehab, E.; Salonitis, K.; Suder, W. Experimental Investigation of Productivity, Specific Energy Consumption, and Hole Quality in Single-Pulse, Percussion, and Trepanning Drilling of IN 718 Superalloy. Energies 2019, 12, 4610. [CrossRef]

3. Um, J.; Stroud, I.A.; Park, Y.-K. Deep Learning Approach of Energy Estimation Model of Remote Laser Welding. Energies 2019, 12, 1799. [CrossRef]

4. Khan, A.M.; Jamil, M.; Salonitis, K.; Sarfraz, S.; Zhao, W.; He, N.; Mia, M.; Zhao, G. Multi-Objective Optimization of Energy Consumption and Surface Quality in Nanofluid SQCL Assisted Face Milling. Energies 2019, 12, 710. [CrossRef]

5. Wang, J.; Fei, Z.; Chang, Q.; Li, S. Energy Saving Operation of Manufacturing System Based on Dynamic Adaptive Fuzzy Reasoning Petri Net. Energies 2019, 12, 2216. [CrossRef]

6. Salonitis, K.; Jolly, M.; Pagone, E.; Papanikolaou, M. Life-Cycle and Energy Assessment of Automotive Component Manufacturing: The Dilemma between Aluminum and Cast Iron. Energies 2019, 12, 2557. [CrossRef]

7. Benedetti, M.; Bonfà, F.; Introna, V.; Santolamazza, A.; Ubertini, S. Real Time Energy Performance Control for Industrial Compressed Air Systems: Methodology and Applications. Energies 2019, 12, 3935. [CrossRef] 
8. Kähkönen, S.; Vakkilainen, E.; Laukkanen, T. Impact of Structural Changes on Energy Efficiency of Finnish Pulp and Paper Industry. Energies 2019, 12, 3689. [CrossRef]

9. Peng, C.; Peng, T.; Zhang, Y.; Tang, R.; Hu, L. Minimising Non-Processing Energy Consumption and Tardiness Fines in a Mixed-Flow Shop. Energies 2018, 11, 3382. [CrossRef]

10. Saxena, P.; Stavropoulos, P.; Kechagias, J.; Salonitis, K. Sustainability assessment for manufacturing operations. Energies 2020, 13, 2730. [CrossRef] 